\title{
The Effect of CEO Endorsement on Consumers' Brand Attitude
}

\author{
Shaoqing Zhang \\ Quanzhou Normal University \\ 398 Donghai Ave, Chen Shouren Business School \\ \& Private Economic Development Research Institute \\ Quanzhou Normal University, Quanzhou, Fujian \\ China \\ Yuan Zhang \\ Xiamen University \\ 422 South Siming Rd., School of Management \\ Xiamen University,Xiamen, Fujian \\ China
}

\begin{abstract}
In advertising practice, there is an increasing number of Chief Executive Officers (CEOs) endorsing their own products, which has been lack of attention on theoretical research. Based on the attribution theory and source model theory, we conducted a 2 (CEO endorsement: yes vs. no) $\times 2$ (brand reputation: high vs. low) $\times 2$ (cognitive need: high vs. low) between-subject design to investigate the mechanism and boundary of effects of CEO endorsement on consumers' brand attitude. The results of current empirical research indicate that: (1) CEO endorsement significantly increase consumers' brand attitude; (2) perceived trust plays a mediating role in the effect of CEO endorsement on consumers' brand attitude; and (3) compared with consumers' cognitive needs, brand reputation can significantly modify the effect of CEO endorsement on consumers' brand attitude. The present research enriches the CEO endorsement theory and provides certain theoretical guidance for companies when applying the theory to advertising practice.
\end{abstract}

Keywords: $\boldsymbol{C E O}$ endorsement; perceived trust; brand reputation; consumers' cognitive need; brand attitude

The Effect of CEO Endorsement on Consumers’ BrandAttitude

\section{IIntroduction}

There are four types of endorsers in commercials, namely, celebrities, experts, typical consumers and CEOs (Friedman \& Friedman, 1979), among which the first type is most favored by industry leaders as endorsers for their products, and the last one is quite special. Friedman and Friedman (1979) pointed out that, compared with celebrities and typical consumers, CEOs, as endorsers, can better convey the idea of professionalism. In addition, in advertising practice, CEOs of outstanding companies have been found to be increasingly involved in the endorsement of their products, such as Ou Chen of JUMEI.COM and Mingzhu Dong of GREE. Why can endorsements of CEOs affect consumers' brand attitude? Issuch a CEO-endorsement strategy applied to all companies? Are CEOs, as a unique group of employees, more persuasive than others in the organization from the perspective of customers? Therefore, it is crucial important for management practice to answer the questions of "Why should companies adopt the CEO-endorsement strategy?" and "How can companies apply the CEOendorsement strategy?"

Previous literatures have investigated the effect of different endorser types on consumers' brand attitude from various perspectives. For example, Atkin and Block(1983) pointed out that endorsers are an important information source of advertisement, which can influence consumers' brand attitude with their own characteristics. This has been proven by other scholars, such as Patzer (1983) and Ohanian (1991). Moreover, Wang and Ma (2004) found that factors, such as the compatibility between the endorser and the product, can have positive influences on consumers' brand attitude and purchasing intention. 
Zhang and Zhao (2016) investigated the effect of immoral or illegal behaviors of endorsing celebrities on consumers' brand attitude from the perspective of perceived moral evaluation. However, there have been no indepth investigations into the internal function mechanism and boundary of CEO endorsements. Neither have the two key questions "Why should companies adopt the CEO-endorsement strategy?"or"How can companies apply the CEO-endorsement strategy?"been answered.

Therefore, this paper aims to explore the mechanism and boundary of the effect of CEO endorsements on consumers' brand attitude based on the attribution theory and Source Model Theory (SMT) and analyze the path of the effect of CEO endorsement on consumers' brand attitude, in order to answer these two questions. And the findings of this paper will contribute to the theoretical research on the effect of CEO endorsement on consumers' brand attitude and serve as the theoretical guidance for companies when adopting this strategy in practice.

\section{Theoretical Background and Research Hypothesis}

\subsection{The Attribution Theory and Brand Attitude}

Attribution refers to the process through which people analyze the behavior of others and themselves to identify its nature and deduce the cause. In other words, it is a process of explaining and deducing the causes for the behaviors of others or themselves. Jones and Davis (1966) pointed out the concepts of internal and external attribution. According to the two concepts, when attributing the behavior of an individual, the observer tended to observe the individuals' behavior and outcome, and then deduce and determine the potential intention and motivation of such a behavior. For consumers' brand attitude, Lutz (1989) argued that brand attitude was the idea of the recipient toward information, which was a gradual behavioral tendency of favor or disfavor displayed in response to advertising stimuli. Rossiter and Percy (1997) further pointed out that brand attitude was an overall evaluation made by customers to judge whether a brand can satisfy their needs. They also showed that brand attitude consisted of cognitive and emotion factors, in which the former guided consumers' behavior, whereas the latter stimulated their behaviors.

Silvera and Austad (1995) pointed out that consumers tended to deduce the behavioral motivation of endorsers, which in turn influenced their attitude towards celebrities and the endorsed brands. According to the attribution theory, consumers attribute the motivation of endorsers' behaviors and judge whether endorsers recommend products due to the internal motivation of sharing the items they really trust and like, or the external motivation based on utilitarian purposes, as a result, different brand attitudes are generated. In this process, consumers can only make simple and interest-related deductions on the identity of endorsers, due to the lack of emotional bond between consumers and endorsers. However, CEO is a special employee of an organization. According to the attribution theory, if he or she endorses the products of the organization, consumers may attempt to associate the CEO's profession and position with his or her represented benefit, thus believe that the CEO's integrity corresponds with the product quality. In other words, CEOs endorse with their reputation and social status. Compared with other employees in the organization, CEOs are more likely to be trusted by customers, and consumers believe that CEOs are fully confident that their own products are superior to those of other companies and really trust and love them. This explains why Mingzhu Dong, former CEO of GREE, chose to endorse their air conditioners. Therefore, it can be reasoned that compared with other employees in the organization, CEOs may impress customers with different feelings through their endorsements of products, thus shaping the consumers' brand attitude. Based on the above discussion, the following hypotheses is proposed,

$\mathrm{H} 1$ : CEO endorsement positively influences consumers' brand attitude

\subsection{Source Model Theory (SMT) and Perceived Trust}

Source Model Theory (SMT) originated from the Source Credibility Theory (SCT) and Source Attractiveness Theory (SAT). According to SMT, due to the combined action of the credibility and attractiveness of source information, the advertising endorsement brings effectiveness in most cases (Sternthal\& Craig, 1973). Then Ohanian (1990) further pointed out that source credibility consisted of three interconnected components, namely, professionalism, reliability and appeal. He suggested that professionalism referred to the professional knowledge embedded in the advertised product, reliability indicated the guaranteed credit or objectiveness of the idea, and appeal could be measured in terms of the physical appearance and characteristics of the endorser. In other words, source credibility is the source of information with positive trait that influences how recipient obtains information and consumers' determination of the effect of the obtained information relying on their perceived credibility of the information source. 
Perceived trust is the willingness of consumers to trust the capability and facility of a company to fulfill its commitments, when they confronted with uncertainty or risk (Hagtvedt, 2011). The position of Chief Executive Officer in a company represents a person' career achievement and status, which is closely connected with the organization's brand reputation. As a result, when the CEO endorses the product of the company, customers would have an overall impression of the character and capability of him or her, associating aspects, such as profession, personality, appearance, social status and temperament, with the properties of the product he or she endorses, so as to analyze and judge the credibility of advertisements. Therefore, the social status of CEOs is an information source of a positive trait that influences consumers' acceptance of the endorsed brand, and consumers would rely on their perception of credibility of the information source to make decision. According arguments above, $\mathrm{H} 2$ is proposed.

H2: Perceived trust plays a mediating role in the effect of CEO endorsement (vs. no) on consumers' brand attitude. Specifically, CEO endorsement (vs. no) can positively influence consumers' perceived trust, which will in turn have a positive effect on consumers' brand attitude.

\subsection{Consumer's Cognitive Need}

Consumer's cognitive need refers to individuals' thinking preference. Consumers' cognitive need is a personal trait indicating whether consumers enjoy thinking, which has a profound effect on the width and depth of their collation, abstraction and assessment of information (Sadowski \& Cogburn, 1997). Cacioppo and Petty (1982) pointed out that people with high cognitive needs preferred complex tasks, who would collect relevant information extensively and conduct in-depth processing to find the inner logic among phenomena. In contrast, peoplewith low cognitive needs preferred simple tasks, who were reluctant to make unnecessary cognitive efforts, likely to ignore information and unwilling to carry out in-depth information processing. In addition, consumers' cognitive needs can modify the effectiveness of advertisements. Putrevu, Tan and Lord (2004) indicated that consumers with high cognitive needs possessed more complex cognitive structures, so that they wereable to better understand and process the complex videos and texts in advertisements, generating even more vivid association and imagination. Meanwhile, Malhotra (1982) found that consumers with low cognitive need werelikely to be overwhelmed by the enormous amount of advertisement, so that they tended to passively receive such information. Therefore, when dealing with CEO endorsements (vs. no), compared with consumers with low cognitive needs, consumers with high cognitive needs are more likely to process the identity information of the endorser, generating positive associations and different brand attitudes. Therefore, $\mathrm{H} 3$ is proposed.

H3: Consumers' cognitive needs (high vs. low) can modify the effect of CET endorsement (vs. no) on their brand attitude. Specifically, when aCEO endorses their own brand, compared with consumers with low cognitive needs, those with high cognitive needs are more likely to be positive towards the brand.

\subsection{Brand Reputation}

Brand reputation is generally presented through brand identification and brand recall. Brand identification refers to the ability of consumers to identify the impression of a certain brand. In other words, when a consumer with brand-identification ability notices a specific brand, he or she can precisely recognize it based on the pre-existing brand impression or a clue. Brand recall means that, when consumers think of a certain product, they can recall a particular brand without any hints. Kardes, Posavac and Cronley (2004) pointed out that consumers tend to initiate brand identification and brand recall spontaneity and make decisions accordingly. Thus, it can be deduced that CEOs of companies with high brand reputation, who endorse their own products, will be considered as persuasive evidence seriously by consumers, which will help consumers to generate favorable brand attitude. On the contrary, whena non-CEO employee in the organization is involved in the endorsement, his or her low relevance to the product may be considered as insufficient evidence by consumers, and there may even be doubts over his or her qualification for the practice, which will generate unfavorable brand attitude of consumers. When it comes to companies with low brand reputation, the endorsements undertaken by their CEOs will also be regarded as evidence by consumers, which are, however, less convincing, thus having no positive effect on their brand attitude. Moreover, consumers believe that non-CEO staffs showing up in the advertisements of their products are more likely to be superficially involved, whose efforts will be considered as peripheral clues of brand cognition, which has no effect on the consumers' brand attitude. Therefore, $\mathrm{H} 4$ is proposed. 
H4: Brand reputation (high vs. low) cans modify the effect of CEO endorsement (vs. no) on consumers' brand attitude. Specifically, compared with CEO endorsements (vs. no) of companies with low brand reputation, those with high reputation will have differential effects on consumers' brand attitude.

To sum up, according to the attribution theory, CEO endorsement (vs. no) has positive effects on consumers' brand attitude. In addition, according to the SMT, perceived trust may play a mediating role in the relationship between CEO endorsement and consumers' brand attitude, while brand reputation and consumers' cognitive needs can modify this process. Therefore, the conceptual model of this paper is shown in Figure 1.

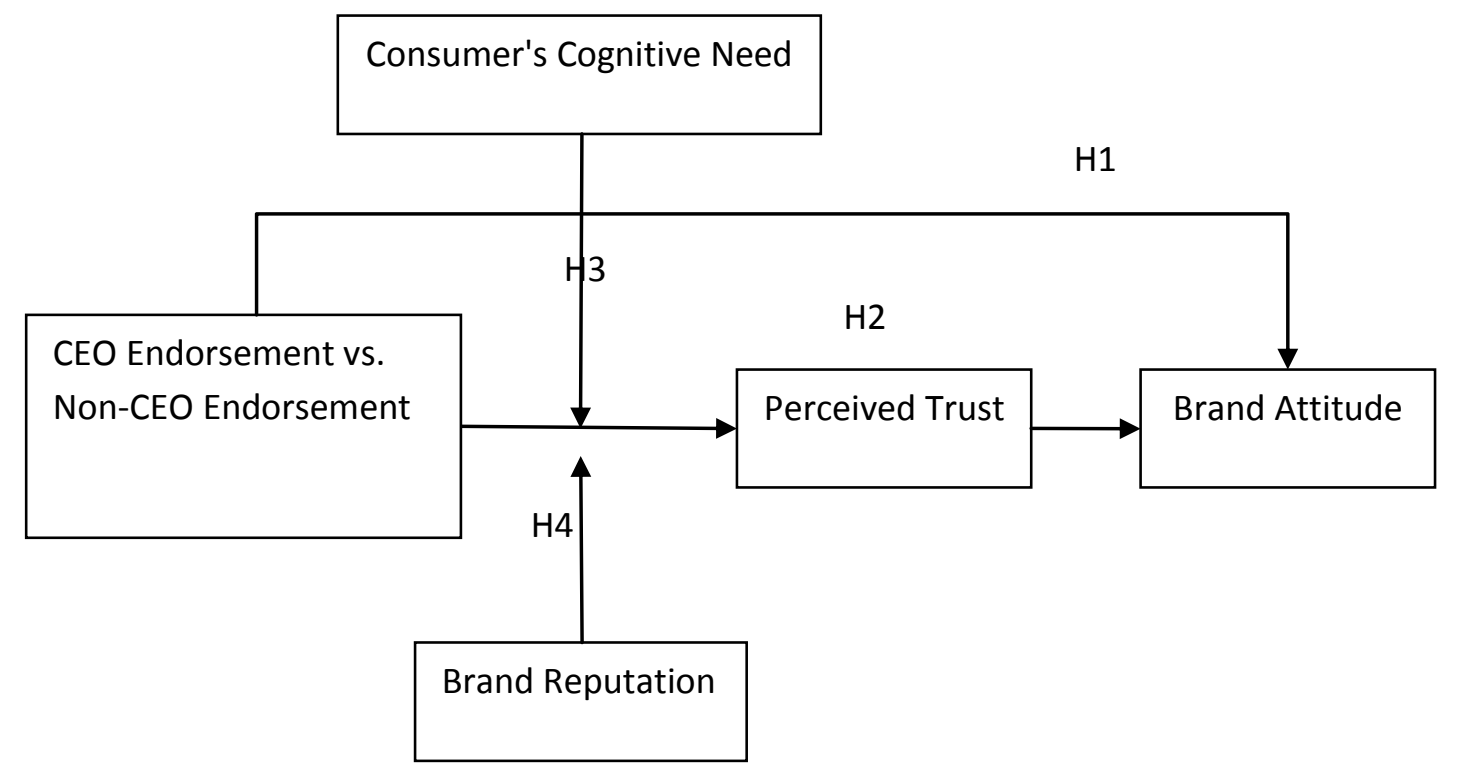

\section{Research Design}

Figure 1:Conceptual model

\subsection{Pretest and Experiment Materials}

The research selected college students, who frequently consume fast food brands, such as KFC and McDonald's, as subjects, since they are more or less involved with advertisements of products like chicken wings and, especially, hamburgers. To ensure that the experiment results can achieve external validity, the current research conducted pretest to select appropriate, actual brands and corresponding CEOs as experiment stimuli. It was conducted among students in marketing at a Business School in Fujian, China. There are 36 sophomores taking part in this pretest in total, who were placed in nine four-member groups. First, they were instructed to discuss and recall "three familiar hamburger brands", and then write down "two brands of, respectively, the highest and lowest reputation". A total of 7 hamburger brands were recalled, where the high recall frequency of brand reputation peaked at 19 person-time (KFC), while the low recall frequency of brand reputation peaked at 13 person-time (Dicos). Therefore, these two companies were chosen as the experiment targets, with Jingshi Su, the KFC CEO (China), and, Yingzhou Wei, Dicos CEO, acting as brand endorsers. Meanwhile, Jilin Han and Yuxin Wang, brand managers of KFC (China) and Dicos, respectively, were selected as non-CEO endorsers of the control group.

\subsection{Experiment}

\subsubsection{Participants and design}

It is a requirement of the current research that all participants possess certain knowledge of the endorsed brands. Therefore, to ensure the accuracy and validity of all the collected data, consumers who experienced in these two restaurants and were familiar with their brands were selected as participants prior to the situation description at the beginning of the questionnaire through "Question 1: Have you ever purchased KFC (Dicos) products? (Yes or No)" and "Question 2: How much do you know KFC (Dicos)? (1-7)".

168 students from a university in Fujian Province, China participated in this experiment, and 21 students with invalid questionnaires and inadequate knowledge of the selected brands were removed. 
Finally, the date gathered from 147 participants was included in the analysis. To verify the hypotheses, a 2 (CEO endorsement: yes vs. no) $\times 2$ (brand reputation: high vs. low) $\times 2$ (cognitive need: high vs. low) between-subject design was used.

Considering the fact that KFC (China) has actually adopted the practice of CEO endorsement, while Dicos has not, and under the situational experiment setting with real brands, the manuscript of the statement of Jingshi Su, CEO of KFC (China) in the advertisement was selected as the sample for all the other three subjects, and only the identity of each endorser was revealed, in order to guarantee the validity of the research results. The manuscript is as follows:

I'm Jingshi Su, CEO of KFC (China) / Jilin Han, Brand Manager of KFC (Yingzhou Wei, CEO of Dicos / Yuxin Wang, Brand Manager of Dicos), and this is what I want to tell you:

For KFC (Dicos), food security is always our first priority. There are over 4,500 chains of KFC in China, each of which is required to follow the food security standards "to the letter". In addition, we at KFC (Dicos) use the white feather chicken, a globally adopted breed, which is raised with absolutely no harmonic additives. There are 25,000 KFC employees here in China, which means that we are responsible for the welfare of 25,000 Chinese families. Moreover, we at KFC (Dicos) are obliged to be responsible for the health of each Chinese consumer. Therefore, I hereby promise on behalf of KFC (Dicos) that each and every piece of our product is totally safe.

\subsubsection{Procedures}

First, the participants were randomly assigned into one of four experiment group, each of which was assigned a questionnaire under a different experiment situation. Then the participants read instructions and answered the first two questions concerning respectively their experience of purchasing KFC (Dicos) products and their familiarity with the brand on a scale of seven. Afterwards, they filled out measuring scales regarding brand attitude, level of cognitive needs and perceived trust. Finally, they provided basic personal information, such as gender and age.

\subsubsection{Measurement of variables}

CEO endorsement was the independent variable, which has two levels "yes" and "no". In the experiment, the Brand Manager of the organization was selected to represent the non-CEO employees. Perceived trust was the mediating variable. The Hagtvedt (2011) scale was adopted, which consisted of two choices, namely "I believe that companies using CEO endorsement are credible" and "I believe that companies using CEO endorsement are reliable", to measure consumers' trust in the endorsing advertisements. The credibility $\alpha$ of the internal consistency was 0.853. Brand attitude was the dependent variable, and the scale of Mitchell and Olson (1981)was adopted here, which consisted of five questions, measuring consumers preference, interest, trust and desire for a certain brand. The credibility $\alpha$ of the internal consistency was 0.869 . Consumer's cognitive need and brand reputation were moderating variables. The scale of prior research (Yi et al., 2005) was adopted for consumer's cognitive need, which had been adapted from the cognitive needs scale of Cacioppo and Petty (1982) and is especially applicable for college students. There were 17 questions, including nine reverse items, and the credibility $\alpha$ of the internal consistency was 0.822 . Meanwhile, brand reputation was measured through manipulating the experiment materials. All the scales adopted the Likert7 point measurement system, where " 1 " indicates "strongly disagree", while "7" refers to "strongly agree".

4Empirical Analysis

\subsection{The Effect of CEO Endorsement (Vs. No) on Consumers' Brand Attitude}

H1 stated that, among endorsers within an organization, the CEO had positive effects on consumers' brand attitude. The results of the ANOVA analysis indicated that consumers' brand attitude was significantly higher when a company's product was endorsed by the CEO $\left(\mathrm{M}_{\mathrm{CEO}}=4.42\right)$ d than by non-CEOs $\left(\mathrm{M}_{\text {non-CEO }}=3.83\right) 2$ $(\mathrm{F}=21.019, \quad \mathrm{P}<0.001)$. Therefore, $\mathrm{H} 1$ was supported.

\subsection{The Mediating Effect of Perceived Trust}

$\mathrm{H} 2$ stated that perceived trust played a mediating role in the effect of CEO endorsement (vs. no) on consumers' brand attitude. First, the hierarchical regression method was adopted through referring to the testing procedure of mediating effects proposed by Wen et al. (2004), and following the steps suggested by Baron and Kenny (1986). The statistical results were shown in Table 1, where CEO endorsement (vs. no) had a significantly positive effect on consumers' brand attitude in M4 $3(\beta=0.338, \mathrm{P}<0.01)$, and on perceived trust in $\mathrm{M} 2(\beta=0.289, \mathrm{P}<0.01)$. 
In addition, CEO endorsement (vs. no) had a significant effect on consumers' brand attitude in M5 after crossing the mediator of perceived trust $(\beta=0.262, \mathrm{P}<0.01)$, and perceived trust still had a significant effect on consumers' brand attitude $(\beta=0.263, \mathrm{P}<0.01)$. Thus, it could be seen that perceived trust indeed played a mediating role in the effect of CEO endorsement (vs. no) on consumers' brand attitude, which supportedH2.

Second, the Bootstrap instrument of Hayes (2013) was utilized based on the testing method of mediating effects recommended by Zhao et al. (2010), to select 5,000 samples through the bias-corrected Bootstrapping method, which was followed by the mediating effect analysis. Within the confidence interval of $95 \%$, the mediating effect of perceived trust was significant (LLCI $=0.0328, \mathrm{ULCI}=0.2481$, excluding 0 ) ${ }^{\theta}$, the effect size was 0.14 and the direct effect of CEO endorsement (vs. no) on consumers' brand attitude is still significant (LLCI $=0.0408$, ULCI $=0.2772$, excluding 0) 5 . It could be seen that part of the mediating effect of perceived trust was still significant when examined using the analysis procedure of mediating effect proposed by Zhao et al. (2010).

\subsection{The Moderating Effect of Consumers' Cognitive Need}

H3 stated that consumer's cognitive need (high vs. low) moderated the effect of CEO endorsement on consumer's brand attitude. When the CEO endorsed the product of his or her company, consumers with high cognitive needs, rather than those with low cognitive needs, would have a positive effect on their brand attitude. The result of the ANOVA analysis indicated that the two-dimensional interaction between CEO endorsement (vs. no) and consumer's cognitive need (high vs. low) was insignificant ( $\mathrm{F}=0.21, \mathrm{P}=0.647>0.1$ ), which did not support $\mathrm{H} 3$.

\section{Table1: The Mediating Effect of Perceived Trust}

\begin{tabular}{|c|c|c|c|c|c|}
\hline \multirow{2}{*}{ Dependent Variable } & \multicolumn{2}{|c|}{ Perceived Trust } & \multicolumn{3}{|c|}{ Brand Attitude } \\
\hline & M1 & M2 & M3 & M4 & M5 \\
\hline \multicolumn{6}{|l|}{ Control variable } \\
\hline $\begin{array}{l}\text { experience } \\
\text { Brand knowledge }\end{array}$ & $\begin{array}{l}.04 / \\
.177\end{array}$ & .116 & $\begin{array}{l}.15 / \\
.164\end{array}$ & $\begin{array}{l}.175 \\
.093\end{array}$ & $\begin{array}{l}.159 \\
.062\end{array}$ \\
\hline Age & -.007 & -.043 & .049 & .007 & .018 \\
\hline Gender & .165 & .150 & -.071 & -.089 & -.128 \\
\hline \multicolumn{6}{|l|}{ Independent Variable } \\
\hline $\begin{array}{l}\text { CEO endorsement (vs. } \\
\text { no) }\end{array}$ & & $.289 * *^{\mathrm{a}}$ & & $.338 * *^{\mathrm{a}}$ & $.262 * *^{\mathrm{a}}$ \\
\hline \multicolumn{6}{|l|}{ Mediator } \\
\hline Perceive trust & & & & & $.263 * *^{\mathrm{a}}$ \\
\hline $\mathrm{R}$ square & .064 & .143 & .079 & .187 & .246 \\
\hline$\triangle R$ square & .038 & .113 & .079 & .108 & .059 \\
\hline$\Delta F$ & $2.429 *^{\mathrm{a}}$ & $13.002 * *^{\mathrm{a}}$ & $3.028 * *^{\mathrm{a}}$ & $18.741 * *^{\mathrm{a}}$ & $10.986^{* * \mathrm{a}}$ \\
\hline
\end{tabular}

\subsection{The Moderating Effect of Brand Reputation}

H4 stated that brand reputation (high vs. low) moderated the effect of CEO endorsement (vs. no) on consumers' brand attitude. Consumers would generate more positive attitude towards the advertisement starred by the CEO of a company with a high brand reputation rather than a low one. The result of the ANOVA analysis revealed that the two-dimensional interaction between CEO endorsement (vs. no) and brand reputation (high vs. low) was significant $(\mathrm{F}=3.508, \mathrm{P}=0.06<0.1)$. Figure 2 showed that there was no significant difference between the consumers' brand attitude to $\mathrm{CEO}$ endorsement $\left(\mathrm{M}_{\mathrm{CEO}}=2.96\right)$ and that to non- $\mathrm{CEO}$ endorsement $\left(\mathrm{M}_{\text {non-CEO }}=2.86\right)$ $(\mathrm{F}<1, \mathrm{P}=0.481>0.1)$ when the brand reputation was low, while consumers' brand attitude to CEO endorsement $\left(\mathrm{M}_{\mathrm{CEO}}=3.76\right)$ was significantly higher than that to non-CEO endorsement $\left(\mathrm{M}_{\text {non-CEO }}=3.42\right)(\mathrm{F}=3.261, \mathrm{P}=0.07$ $<0.1)$ when the brand reputation was high. Thus, H4 was supported. 


\section{Figure 2: The moderating effect of brand reputation}

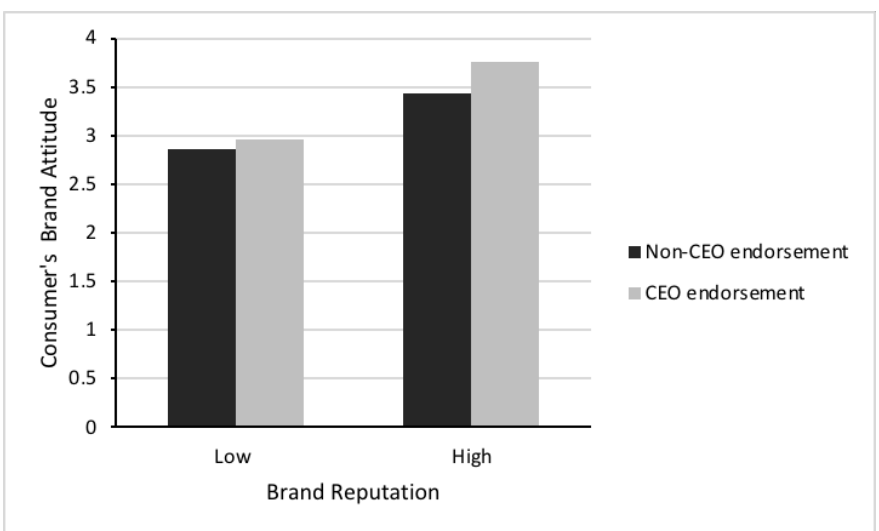

\subsection{Brief Summary of the Results}

To sum up, Figure3showed that CEO endorsement (vs. no) had significantly differential effects on consumers' brand attitude, specially, CEO endorsement generated more favorable consumers' brand attitudes than non-CEO endorsement did. In addition, CEO endorsement (vs. no) applied perceived trust as the mediator to influence consumers' brand attitude, and such influences moderated by brand reputation. As a result, hypotheses 1, 2 and 4 have been proven, with the only exception of $\mathrm{H} 3$.

Figure 3: The result analysis of conceptual model

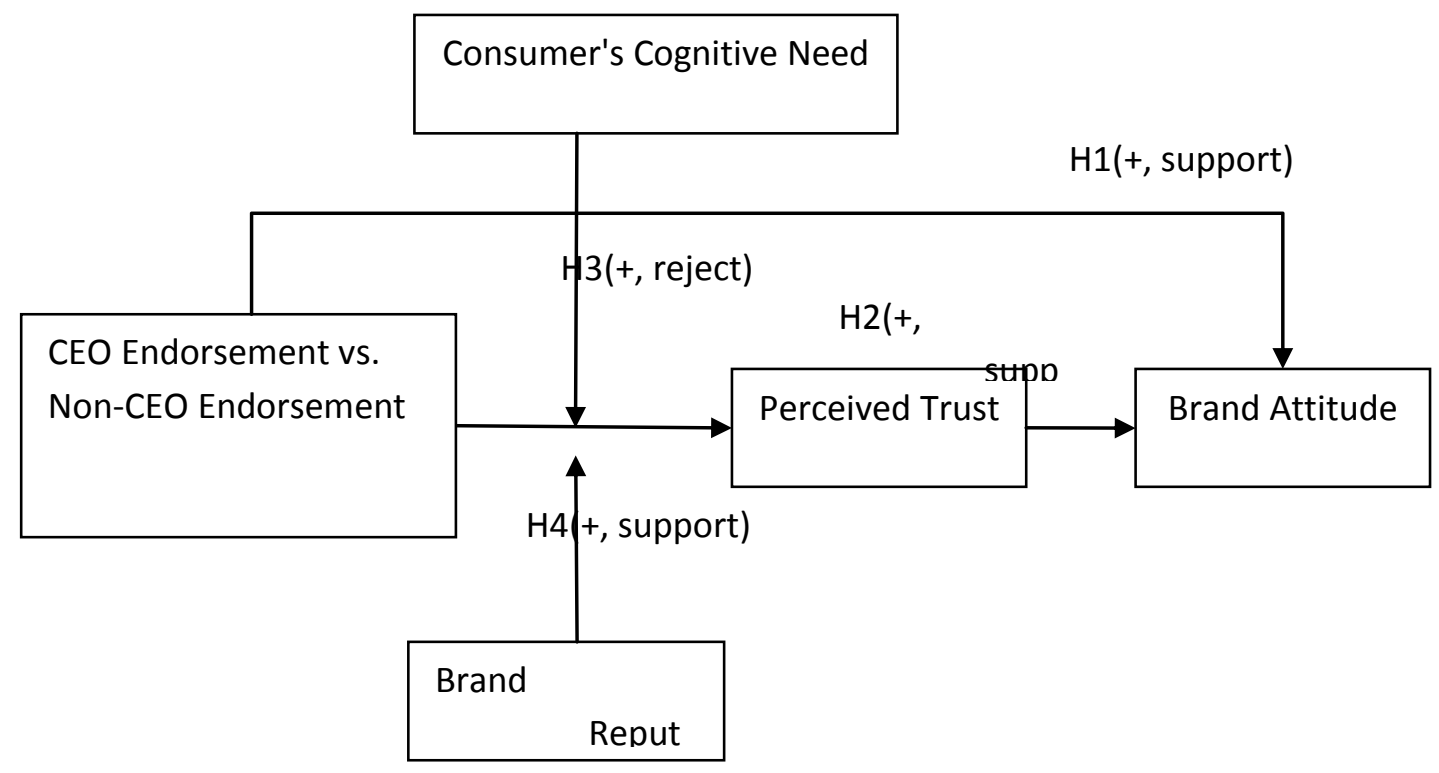

\section{General Discussions}

\subsection{Research Conclusion}

This paper builds on literature review to propose research questions, construct the theoretical research model and test hypotheses using experiment data, thus drawing the following four conclusions. To begin with, CEO endorsement (vs. no) has significantly positive effects on consumers' brand attitude. Results of current research indicated that, compared with non-CEO endorsement, CEO endorsement generated more favorable consumers' brand attitude. Since there little emotional connection between consumers and the endorser, it the deduction based on interest relevance that determines whether the CEO endorsement be trusted. In other words, the CEO of a company, as a symbol of career success and social status, bound the person in the position tightly with the organization's brand reputation. According to the attribution theory, consumers tended to associate the profession, personality, appearance, social status and temperament of CEOs with the brand of the company they endorse, believing that CEO recommend the products of their own companies out of genuine trust and love. By that logic, consumers would view such endorsements as pledges CEOs that guaranteed by their credit and social reputation, and so on, thus deducing that the products reliable, which eventually generate favorable brand attitude. 
Second, perceived trust hada mediating effect in the effect of CEO endorsement (vs. no) on consumers' brand attitude. According to the Source Model Theory (SMT) of information, the social status of the CEO is the source of information with positive trait that consumers to accept the endorsed product or brand, and consumers made judgments based on the perceived credibility of the information source (Atkin \& Block, 1983). Distinguished from other employee in an organization, the CEO both social status and career success, so his or her endorsement enhance the influence of the credibility of the product and promoted consumers' perceived trust, thus gaining consumers' favorable brand attitude. Therefore, companies that adopt the CEO endorsement strategy should add information that demonstrates the CEO's credibility and authoritativeness, in order to improve consumers' perceived trust.

Third, consumers' cognitive nee (high vs. low) did not moderate the effect of CEO endorsement (vs. no) on their brand attitude. Consumers' cognitive need was one of their thinking preferences, which also indicated their personal trait relative to the ability to enjoy thinking. It a process in which thinking can be started. However, consumers' cognitive need was not effectively when the CEOs (vs. no) endorsed their own products, probably due to the experimental situation was designed to be a simple daily behavior of purchasing hamburgers, impeding their acceptance of the information in the CEO endorsement (vs. no) and thus failing to be proven by the data.

Finally, brand reputation moderated the effect of CEO endorsement (vs. no) on consumers' brand attitude. For consumers, a non-CEO endorser is different from the CEO endorser only in their position in a company with a relatively lower brand reputation. Based on this logic, consumers believe that, compare with non-CEO endorsement, CEO endorsement higher social risks, but there not much difference in their social impacts. Therefore, there is a lack of purchasing credibility in the information of both types of endorsers, which unlikely to significantly affect the brand attitude. Nevertheless, when the CEO with relatively higher brand reputation a product, the risks for his or her endorsement rise dramatically due to the increased exposure, which will be seriously considered by consumers as persuasive evidence. In contrast, consumers believe that non-CEO endorsers are less involved in the company than CEOs do, making it impossible for the failure in their endorsements to cause extensive impact. In other words, CEO endorsement can provide consumers with more perceived trust, so it can better improve consumers' brand attitude than non-CEO endorsement. And there are significant differences between the two types of endorsements. Therefore, a company should adopt the CEO endorsement strategy when its brand reputation is at the peak, which will enhance consumers' perceived trust.

\subsection{Research Contributions}

\subsubsection{Theoretical contributions}

The research focused on the increasingly popular practice of "corporate CEOs endorsing their own products" and investigates the promotional effect of companies" "CEO endorsement" on the basis of the attribution theory. This paper also explains the mechanism of the internal influence of CEO endorsement (vs. no) on consumers' brand attitude through introducing the mediating variable of "perceived trust" based on the Source Model Theory (SMT). In addition, the moderating effects of consumers' cognitive need and corporate brand reputation were examined. In conclusion, the research not only explained corporate CEO endorsement, but also applied the "attribution theory" and "Source Model Theory (SMT)" to further reveal its underlying mechanism, specify its boundaries and answer key question of "Why should companies adopt the CEO-endorsement strategy?", enriches the theoretical research on CEO endorsement on brand attitude and further expand the CEO endorsement theories, which are of great theoretical significance.

\subsubsection{Practical implications}

The research can provide certain theoretical guidance for companies opting for the CEO endorsement decisionmaking. First, with the growth of the organization and the promotion of its brand reputation, a company may consider the CEO to endorse their own product, if possible. Second, it is vital important that the CEO should possess the ability to gain consumers' "trust". Therefore, his or her authoritativeness and halo need to be supplemented to a certain extent in order to establish a closer relation between the CEO and the company's product through the "halo effect", thus enhancing consumers' perceived trust. Finally, the industry environment of a company may affect the choice of CEO endorsement. For example, consumers' involvement in the industry of fast-moving consumer goods is just simply the purchasing process, during which CEO endorsement is less productive in the advertising practice of brands with low reputation than those with high reputation. Therefore, consumers' brand attitude can only be promoted by CEO endorsement in industries with high reputation. This 
helps to answer another key question in the research "How can companies apply the CEO-endorsement strategy?" That is, CEO endorsement is really an effective strategy for brands with high reputation to improve their consumers' brand attitude, however, for brands with low reputation, it is needed more deliberation before applying CEO endorsement in advertisement.

\subsection{Direction for Future Research}

There are still some limitations in the research, such as the selections of the industry of fast-moving consumer goods and CEO endorsers, as well as the methods to start and measure consumers' cognitive needs. In addition, the participants were all college students, ignoring the possible differences in the acceptance of the effect of CEO endorsement among middle-aged and elderly consumers who are relatively more mature in mind. Moreover, since field study has become an important field for future research, a survey on the effect of corporate CEO endorsement conducted among the general public through field study may yield more convincing results. Finally, whether CEO endorsing products or not affecting consumer's brand attitude has been discussed in this paper, however, not all CEOs have good reputation. Does the valence of CEOs' reputation also influence consumer's attitude toward products CEO endorsed? It is worthy to discuss in future.All the above-mentioned limitations need to be overcome in future studies.

This paper is one of the achievements of the Private Economic Development Research Institute of Quanzhou Normal University. This research is also supported by Planning Foundation Project for Humanity and Social Science Research of the Ministry of Education of the People's Republic of China (16YJA630013). Correspondence concerning this article should be addressed to Yuan Zhang.

Note:

\$2: Here, $\mathrm{M}_{\mathrm{CEO}}$ and $\mathrm{M}_{\mathrm{Non}}{ }^{-} \mathrm{CEO}$ refer to the mean value of consumer's brand attitude under $\mathrm{CEO}$ endorsement and Non-CEO endorsement condition, respectively.

3: M1 to M5,showed in this paper and in Table 1 as well, refer to regression models with different dependent variables, different independent variables and mediation variable, which are applied to test hypothesis.

45: CI is the confidence intervals which report the effect size of the mediating effect. LLCI is the low level and ULCI is the upper lever. When zero is excluded out of the interval between low level and upper level, that means the mediating effect is significant.

\section{References}

Atkin, C., \& Block, M. (1983).Effectiveness of Celebrity Endorsers. Journal of Advertising Research, 23(1), 5761.

Baron, R. M.,\& Kenny, D. A.(1986). The Moderator-Mediator Variable Distinction in Social Psychological Research: Conceptual, Strategic, and Statistical Considerations. Journal of Personality and Social Psychology, 51(6), 1173-1182.

Cacioppo, J.T., \& Petty, R.E. (1982). The Need for Cognition. Journal of Personality and Social Psychology, 42(January), 116-131.

Friedman, H.H. \& Friedman, L.(1979). Endorser Effectiveness by Product Type. Journal of Advertising Research, 19(5), 63-71.

Hagtvedt, H. (2011). The Impact of Incomplete Typeface Logos on Perceptions of the Firm. Journal of Marketing, 75(4), 86-93.

Hayes, A. F. (2013). An Introduction to Mediation, Moderation, and Conditional Process Analysis; A Regression Based Approach. New York: Guilford Press.

Jones, E. E., \&Davis, K. E. (1966). From Acts to Dispositions: The Attribution Process in Person Perception. Advances in Experimental Social Psychology, 2, 219-266.

Kardes, F. R., Posavac S. S., \&Cronley, M. L. (2004). Consumer Inference: A Review of Processes, Bases, and Judgment Contexts. Journal of Consumer Psychology, 14(3), 230-256.

Lutz, R.J., \& Mackenzie, S. B.(1989). An Empirical Examination of the Structural Antecedents of Attitude Toward the Ad in an Advertising Pretesting Context. Journal of Marketing Research, 53, 48-65.

Malhotra,N.K. (1982). Information Load and Consumer Decision Making. Journal of Consumer Research, 8(March), 419-430. 
Mitchell. A. A.,\& Jerry C. O.,(1981). Are Product Attribute Beliefs the Only Mediator of Advertising Effects on Brand Attitude?Journal of Consumer Research, 18(8), 318-332.

Ohanion, R. (1990). Construction and Validation of Scale Measure Endorsers' Perceived Expertise, Trustworthiness, and Attractiveness. Journal of Advertising, 19(3), 39-52.

Ohanian, R. (1991). The Impact of Celebrity Spokesperson's Perceived Image on Consumers' Intention to Purchase. Journal of Advertising Research, 31(1), 46-52.

Patzer, G. L. (1983). Source Credibility as a Function of Communicator Physical Attractiveness. Journal of Business Research, 11(2), 229-241.

Putrevu, S., Tan J., \& Lord, K.R. (2004). Consumer Responses to Complex Advertisements: The Moderating Role of Need for Cognition, Knowledge, and Gender. Journal of Current Issues and Research in Advertising. 26(1), 9-24.

Rossiter, J. R., \&Percy, L. (1997). Advertising Communications \&Promotion Management. InternationalEdition: McGrawHill.

Sadowski, C.J., \&Cogburn, H.E. (1997). Need for Cognition in the Big-Five Factor Structure. Journal of Psychology, 131(3), 307-312.

Silvera, D.H., \&Laufer, D. (2005). Recent Developments in Attribution Research and Their Implications for Consumer Judgments and Behavior. Applying Social Cognition to Consumer-focused Strategy (Chapter $3)$.

Sternthal, B., \& Samuel Craig, S. C. (1973). Humor in Advertising. Journal of Marketing, 37 (October), 12-18.

Wang, H.M.,\& Ma, M.C. (2004).An Experiment on the Influence of the Congruence Between the Celebrity and the Product Endorsed on Celebrity Advertising. Psychological Science, 27(1), 198-199.

Wen, Z. L., Chang, L., Hau, K., \&Liu, H.Y. (2004). Testing and Application of the Mediating Effects. Acta Psychological Science, 36(5), 614-620.

Yi, K., Shi J. Q., Cai, Y. Q., \&Wang, L. (2005). The Chinese Version of Need for Cognition Scale. Chinese Mental Health Journal, 19(1), 57-60.

Zhang, S.Q.,\& Zhao, M.(2016).The Influence on Brand Attitude of the Negative Behavior of Star Endorsement: From the Perspective of Moral Evaluation. Social Sciences of Beijing,9, 91-98.

Zhao, X., Lynch, J. G., \&Chen, Q.(2010). Reconsidering Baron and Kenny: Myths and Truths About Mediation Analysis. Journal of Consumer Research, 37, 197-206. 